\title{
ANALISIS EFEKTIVITAS PROGRAM KEMITRAAN DAN BINA LINGKUNGAN PT INDUSTRI KERETA API (INKA) PERSERO PADA UMKM
}

\author{
Anny Widiasmara ${ }^{1)}$ \\ Universitas PGRI Madiun \\ anny.widiasmara@gmail.com
}

\begin{abstract}
Abtract
This research is intended to analyze Partnership and Community Development Program (PKBL) of PT INKA (Persero) at UMKM as one of the program. Corporate Social Responsibility (CSR) and to find out the relationship between the partners of PT INKA (Persero) Partnership and Community Development Program (PKBL). The research was conducted on 50 partners of PT INKA (Persero) located in Madiun Regency. Data Technique uses primary and secondary data. The data were analyzed by descriptive statistic with Likert scale, Importance of Performance Analysis (IPA), and Cross Tabulation Test (Crosstab). The result showed that PT INKA (Persero) Partnership and Community Development Effectiveness Program achieved the program objectives effectively. Based on the result of Cross Tabulation (Crosstab) there is a significant correlation between characteristic of assisted life with coaching program.
\end{abstract}

Keywords: effectiveness, CSR, PKBL, UMKM

Abstrak

Penelitian ini bertujuan untuk menganalisis efektivitas Program Kemitraan dan Bina Lingkungan (PKBL) PT INKA (Persero) pada UMKM sebagai salah satu program Corporate Social Responsibility(CSR) dan untuk mengetahui hubungan karakteristik mitra binaan terhadap efektivitas Program Kemitraan dan Bina Lingkungan (PKBL) PT INKA (Persero). Penelitian dilakukan pada 50 mitra binaan PT INKA (Persero) yang berada di Kabupaten Madiun.Teknik pengumpulan data menggunakan data primer dan sekunder. Pengujian data dilakukan dengan statistik deskriptif dengan skala Likert, Importance Performance Analysis (IPA), dan Uji Tabulasi Silang (Crosstab).Hasil penelitian menunjukkan bahwa Efektivitas Program Kemitraan dan Bina Lingkungan PT INKA (Persero), secara keseluruhan realisasi ketercapaian tujuan program sudah efektif. Berdasarkan hasil Tabulasi Silang (Crosstab) terdapat hubungan yang signifikan antara karakteristik umur mitra binaan dengan program pembinaan.

Kata Kunci: Efektivitas, CSR, PKBL, UMKM

\section{PENDAHULUAN}

Tanggung jawab sosial Nomor : PER- 09/MBU/07/2015 perusahaan bukan sekedar kegiatan ekonomi melainkan juga tanggung jawab terhadap sosial dan lingkungan. Undang-undang Pasal 74 No.40 Tahun 2007 Tentang Perseroan Terbatas diwajibkan untuk melaksanakan Corporate Social Responsibility(CSR).

Program Corporate Social Responsibility(CSR) yang diadakan perusahaan salah satunya adalah Penetapan Peraturan Menteri BUMN Tentang Program Kemitraan BUMN Dengan Usaha Kecil Dan Program Bina Lingkungan merupakan dasar pemanfaatan dana BUMN guna meningkatkan kemampuan Usaha Mikro Kecil dan Menengah (UMKM) agar menjadi tangguh dan mandiri.

PT INKA (Persero) adalah satu-satunya perusahaan industri kereta api di negara ini. PT INKA (Persero) merupakan salah satu perusahaan Badan Usaha Milik 
Negara (BUMN) yang juga Kemitraan dan melakukan kegiatan Program

Bina Lingkungan (PKBL). untuk dana Program Kemitraan dan Adapun rencana dan realisasi Bina Lingkungan sebagai berikut anggaran selama tahun 2013-2015 :

Tabel 1.1 Anggaran Dana Program Kemitraan PT INKA (Persero) Tahun 2013-2015.

\begin{tabular}{lllll}
\hline Tahun & $\begin{array}{l}\text { Unit } \\
\text { MB }\end{array}$ & Rencana anggaran & Realisasi anggaran & $\%$ \\
\hline 2013 & 73 & 1.580 .000 .000 & 1.537 .500 .000 & $97,31 \%$ \\
2014 & 66 & 1.595 .000 .000 & 1.620 .760 .000 & $102 \%$ \\
2015 & 70 & 1.710 .000 .000 & 1.796 .750 .000 & $105 \%$ \\
\hline
\end{tabular}

Sumber Data: PT INKA (Persero)

Tabel 1.2 Anggaran Dana Program Bina Lingkungan PT INKA (Persero) Tahun 2013-2015

\begin{tabular}{llll}
\hline Tahun & Rencana anggaran & Realisasi anggaran & \% \\
\hline 2013 & 70.000 .000 & 51.058 .300 & $63 \%$ \\
2014 & 57.000 .000 & 35.832 .250 & $73 \%$ \\
2015 & 45.000 .000 & 41.480 .500 & $92 \%$ \\
\hline
\end{tabular}

Sumber Data: PT INKA (Persero)

Berikut adalah kualitas piutang mitra binaan PT INKA (Persero) pada Program Kemitraan dan Bina Lingkungan (PKBL):

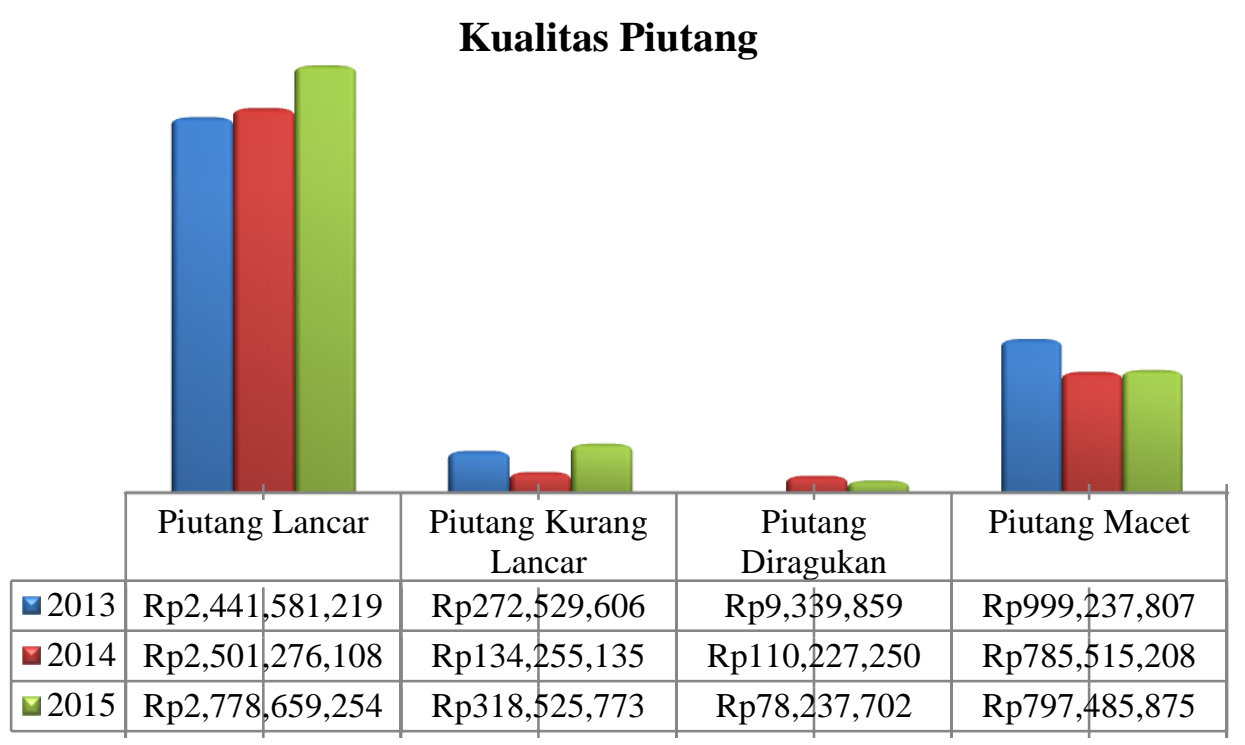

Gambar 1.1 Kualitas Piutang PT INKA (Persero) 
Menurut Widodo (2017: 177)

kriteria evaluasi antara lain: efektivitas, efisiensi, kelayakan politik, kelayakan ekonomis/anggaran dan kelayakan administratif. Dalam penelitian ini penulis menggunakan kriteria efektivitas dalam penilaian program, yang mengacu pada karakteristik mitra binaan diantaranya jenis kelamin, usia, dan pendidikan. Sedangkan, penilaian efektivitas sendiri adalah tujuan Program Kemitraan dan Bina Lingkungan (PKBL) yang meliputi pendidikan, pelatihan, pemasaran, dan pinjaman lunak.

Berdasarkan penelitian terdahulu, Bahannoer (2009) hasil penelitian menunjukkan bahwa PT Pertamina (Persero) Unit Pemsasaran I Medan merupakan salah satu perusahaan BUMN yang melaksanakan Program Kemitraan dan Bina Lingkungan (PKBL) yang menyalurkan kredit kepada Usaha Mikro Kecil dan Menengah (UMKM) bahwa mitra binaan yang diberikan pinjaman mengalami perkembangan. Menurut penelitian Handayani, Darsono dan Widiyanti (2014) Hasil penelitian menunjukkan bahwa program Kredit Ketahanan Pangan Dan Energi (KKPE) yang telah dijalankan sudah efektif, sistem bagi hasil dan program pendampingan budidaya sudah cukup efektif, serta rumah tangga petani tebu mitra binaan belum sejahtera.

Sedangkan menurut penelitian Yulianti (2012) hasil penelitian menunjukkan bahwa program yang dijalankan kurang efektif. Dan hasil penelitian Supriadinata dan Goestaman (2013) menunjukkan hasil bahwa program Corporate Social Responsibility(CSR) yang direncanakan hampir keseluruhan telah dilaksanakan. Namun dalam pelaksanaannya masih terdapat kelemahan-kelemahan sehingga hasil dari pelaksanaan program tersebut belum maksimal.

\section{METODE PENELITIAN}

Metode dasar penelitian ini adalah Statistik deskriptif dengan wawancara, kuesioner dan observasi. Tempat penelitian dilakukan di PT INKA (Persero) J1. Yos Sudarso No.71, Madiun Lor, Madiun, Kota 
Madiun, Jawa Timur 63122, Indonesia. Responden penelitian adalah pihak ataupun kelompok yang menerima Program Kemitraan dan Bina Lingkungan (Mitra Binaan) PT INKA (Persero) di Kabupaten Madiun. Desain penelitian yang akan digunakan adalah jenis penelitian kuantitatif dengan skala Likert. Pengukuran rata-rata dari skala Likert kemudian dipetakan ke rentang skala yang mempertimbangkan informasi interval.

Menentukan nilai jawaban responden yang mengacu pada 5 point dari skala: Likert $:$ Interval $=$

nilai skor jawaban tertinggi-nilai skor jawabon terendah banyaknya kelas

Maka skor jawaban tertinggi adalah 5 dan nilai skor terendah adalah 1 , sedangkan banyaknya kelas disesuaikan dengan skala yang digunakan yaitu 5 kelas (Tanto, dkk, 2012). Setelah besarnya interval diketahui, kemudian dibuat rentan skala sehingga dapat diketahui dimana letak rata-rata penilaian responden terhadap aspek-aspek tujuan program.
Tabel 2.1 Rentan Skala Penilaian Responden

\begin{tabular}{|c|c|}
\hline $\begin{array}{l}\text { Rentan skala } \\
\text { penilaian }\end{array}$ & Keterangan \\
\hline $1,00-1,80$ & $\begin{array}{l}\text { Sangat tidak } \\
\text { setuju/efektif }\end{array}$ \\
\hline $1,81-2,60$ & $\begin{array}{l}\text { Tidak } \\
\text { setuju/efektif }\end{array}$ \\
\hline $2,61-3,40$ & $\begin{array}{l}\text { Kurang } \\
\text { setuju/efektif }\end{array}$ \\
\hline $3,41-4,20$ & Setuju/efektif \\
\hline $4,21-5,00$ & $\begin{array}{l}\text { Sangat } \\
\text { Setuju/sangat } \\
\text { efektif }\end{array}$ \\
\hline
\end{tabular}

(Kadir, 2015: 26)

Teknik analisis data menggunakan Statistik deskriptif adalah statistik yang digunakan untuk menganalisis data dengan cara mendeskripsikan atau menggambarkan data yang telah terkumpul sebagaimana adanya tanpa bermaksud membuat kesimpulan yang berlaku untuk umum atau generalisasi (Sugiyono, 2013: 147).

Tabulasi silang pada prinsipnya menyajikan data dalam bentuk tabulasi yang meliputi baris dan kolom dan data untuk penyajian crosstab adalah data berskala nominal atau kategori. Program SPSS memberikan fasilitas untuk analisis tabulasi silang (crosstab) (Ghozali, 2016: 21). Jadi, untuk mengetahui hubungan antara karakteristik mitra 
binaan dengan efektivitas Program (John Martila and John C. James,

Kemitraan dan Bina Lingkungan 1997)

maka peneliti menggunakan analisis Keterangan:

tabulasi silang (crosstab) dalam Tki : tingkat kesesuaian

penelitian ini.

Importance Performance responden

Analysis (IPA) ini mengaitkan antara $\mathrm{Xi}$ : Skor penilaian tingkat tingkat kepentingan (importance) suatu atribut yang dimiliki obyek kinerja/realisasi

tertentu dengan kenyataan (performance) yang dirasakan oleh pengguna. Importance Performance Analysis (IPA) digunakan untuk mengukur tingkat kepuasan seseorang atas kinerja pihak lain. Tingkat kepentingan tersebut dipetakan dalam diagram kartesius yang disebut Matriks IPA (Rangkuti dalam Fitriyani, 2011). Untuk melihat tingkat kepentingan dan kenyataan suatu program yang diberikan pada mitra binaan sudah berjalan efektif apa belum, perlu ditingkatkan atau bahkan dihentikan maka penulis menggunakan Analisis IPA dalam penelitian ini. Rumus yang digunakan dalam IPA adalah sebagai berikut:

$$
\mathrm{Tki}=\frac{X i}{Y i} \mathrm{x} 100 \%
$$


Matriks IPA terdiri dari empat kuadran yang masing-masing menjelaskan keadaan yang berbeda, yaitu:

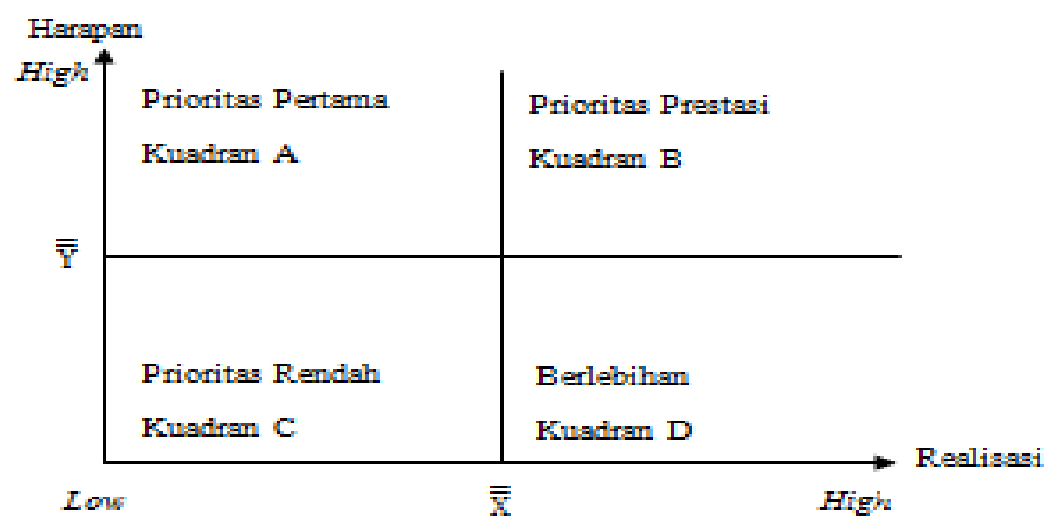

\section{Gambar 2.1 Matriks IPA (Rangkuti, dalam Fitriyani 2011)}

a. Kuadran A (Prioritas Pertama)

Kuadran ini memuat atribut yang dianggap penting oleh mitra binaan tapi kinerja/realisasi atribut tersebut kurang dari apa yang diharapkan.

b. Kuadran B (Prioritas Prestasi) Kuadran ini membuat atribut yang dianggap penting oleh mitra binaan dan pelaksanaannya dianggap sudah sesuai harapan.

c. Kuadran C (Prioritas Rendah) Kuadran ini memuat atribut yang dianggap kurang penting oleh mitra binaan dan kinerja atribut tersebut kurang dari apa yang diharapkan. d. Kuadran D (Berlebihan) Kuadran ini memuat atribut yang dianggap kurang penting oleh mitra binaan sedangkan kinerja perusahaan pada atribut ini terlalu tinggi sehingga dianggap berlebihan. Harus dilakukan efisiensi pada atribut di kuadran ini sehingga bisa menghemat biaya.

\section{HASIL}

Berdasarkan hasil wawancara/angket dengan 50 responden terjadi peningkatan pendapatan rata-rata bersih seperti dijelaskan pada tabel dibawah: 
Tabel 3.1 Pendapatan Responden

\begin{tabular}{lll}
\hline Pendapatan Rata-rata & $\begin{array}{l}\text { Sebelum menjadi } \\
\text { mitra binaan } \\
\text { (Responden) }\end{array}$ & $\begin{array}{l}\text { Sesudah menjadi } \\
\text { mitra binaan } \\
\text { (Responden) }\end{array}$ \\
\hline$<$ Rp 1.000.000 & 30 & \\
Rp 1.000.000-Rp 2.000.000 & 20 & 26 \\
Rp 2.000.000-Rp 3.000.000 & & 22 \\
Rp 3.000.000-Rp 4.000.000 & & 2 \\
Jumlah mitra binaan & 50 & 50 \\
\hline
\end{tabular}

Dari tabel tersebut dapat diketahui bahwa pendapatan bersih rata-rata mitra binaan mengalami peningkatan yang signifikan setelah mengikuti program kemitraan dan bina lingkungan. Mitra binaan berasal dari asal kabupaten Madiun, dan bekerja sebagai pedagang dan wiraswasta. Karakteristik mitra binaan/responden dalam penelitian ini adalah sebanyak 50 mitra binaan.

Berdasarkan hasil wawancara dengan responden, seluruh responden menjadi mitra binaan PT INKA (Persero) dengan tujuan untuk memperoleh modal tambahan dalam usaha, dan ingin mengembangkan usaha yang mereka jalankan. Mitra binaan yang hampir seluruhnya telah berkeluarga ( berstatus menikah) ini sebagian besar memperoleh informasi mengenai progran PKBL ini dari kerabat/keluarga serta dari pihak PT
INKA (Persero) yang mengadakan sosialisasi. Mitra binaan PT INKA (Persero) yang menjadi responden penelitian ini berdasarkan jenis kelamin terdiri dari 29 orang laki-laki dan 21 orang perempuan.. Memiliki usia lebih dari 40 tahun sebanyak 27 orang (54\%), usia 31- 40 tahun sebesar 19 orang (38\%) dan sisanya usia 24-30 tahun sebanyak 4 orang $(8 \%)$.

Berdasarkan tingkat pendidikan terakhir responden yang paling dominan adalah mitra binaan dengan tingkat pendidikan terakhir pada jenjang SMA/SMK sebanyak 27 orang (54\%),. Selanjutnya terdapat 15 orang mitra binaan dengan pendidikan terakhir SD/SMP (30\%). Maka dari itu, mitra binaan perlu dibina melalui program PKBL agar mampu mengembangkan usaha yang dimilki. Sisanya ada 5 orang dengan 
pendidikan D3 (10\%), dan 3 orang dengan tingkat pendidikan terakhir $\mathrm{S} 1(6 \%)$.

Jenis usaha responden yang paling dominan adalah makanan sebanyak 30 mitra binaan (60\%). Jenis usaha makanan ini meliputi aneka keripik, kue, brem dan minuman instant tradisional, dan sisanya jenis usaha selain makanan ada 20 mitra binaan (40\%). Jenis usaha selain makanan ini meliputi alat pertanian, beton, bengkel las, konveksi, mebel alumunium, gerabah, desain interior dan eksterior bangunan.

Berdasarkan lama bermitra, sebagian besar responden bermitra 35 tahun yaitu sebanyak 32 mitra binaan (64\%). Ini terjadi karena pinjaman lunak yang diberikan maksimal dengan tempo 3 tahun/36 bulan. Sebanyak 9 orang telah bermitra kurang dari 1 tahun (18\%), dan sebanyak 9 orang juga telah bermitra selama lebih dari 5 tahun $(18 \%)$.

Uji signifikasi dilakukan dengan membandingkan nilai $r$ hitung dengan $r$ tabel untuk degree of freedom $(d f)=\mathrm{n}-2$, dalam hal ini $\mathrm{n}$ adalah jumlah sampel. Untuk menguji apakah masing-masing indikator valid atau tidak, kita lihat output Cronbach Alpha pada kolom Correlated ItemTotal Correlation. Bandingkan nilai Correlated Item-Total Correlation dengan hasil perhitungan $r$ tabel. Jika r hitung lebih besar dari $\mathrm{r}$ tabel $(\mathrm{n}=50$, maka $r$ hitung=0,279) dan nilai positif maka butir atau pertanyaan dinyatakan valid.

Hasil perhitungan dapat dilihat pada tabel berikut :

Tabel 3.2 Uji Validitas pada realisasi program adalah sebagai berikut:

\begin{tabular}{lllll}
\hline \multicolumn{1}{c}{ Indikator } & $\begin{array}{l}\text { Corrected } \\
\text { Item-Total } \\
\text { Correlation }\end{array}$ & Signifikan & Keterangan \\
\hline $\begin{array}{l}\text { Pinjaman } \\
\text { lunak: }\end{array}$ & Penyaluran dana & 0.431 & 0.000 & Valid \\
$\begin{array}{l}\text { Pembinaan: } \\
\text { Monitoring }\end{array}$ & 0.813 & 0.000 & Valid \\
& $\begin{array}{l}\text { penggunaan dana } \\
\text { Evaluasi } \\
\text { perkembangan usaha }\end{array}$ & 0.695 & 0.000 & Valid \\
& $\begin{array}{l}\text { Penyusunan profil } \\
\text { Pendid }\end{array}$ & 0.922 & 0.000 & Valid
\end{tabular}




\begin{tabular}{lllll} 
Pelatihan: & $\begin{array}{l}\text { mitra binaan } \\
\begin{array}{l}\text { Pendidikan } \\
\text { pelatihan }\end{array}\end{array} \quad$ dan & 0.743 & 0.000 & Valid \\
$\begin{array}{l}\text { Proses komputerisasi } \\
\text { pembukuan }\end{array}$ & 0.455 & 0.000 & Valid \\
$\begin{array}{l}\text { Display } \\
\text { produk/prestasi mitra } \\
\text { binaan }\end{array}$ & 0.842 & 0.000 & Valid \\
Pemasaran & & 0.691 & 0.000 & Valid \\
& $\begin{array}{l}\text { Pameran } \\
\text { Promosi }\end{array}$ & 0.729 & 0.000 & $\begin{array}{l}\text { Valid } \\
\text { Cluster }\end{array}$ \\
\hline
\end{tabular}

Sumber: Perhitungan SPSS

Tabel 3.3 Uji Validitas pada program yang diharapkan mitra binaan adalah sebagai berikut:

\begin{tabular}{|c|c|c|c|c|}
\hline \multicolumn{2}{|c|}{ Indikator } & \multirow{2}{*}{$\begin{array}{l}\text { Corrected } \\
\text { Item-Total } \\
\text { Correlation } \\
0.787\end{array}$} & \multirow{2}{*}{$\begin{array}{l}\text { Signifikan } \\
0.000\end{array}$} & \multirow{2}{*}{$\begin{array}{l}\text { Keterangan } \\
\text { Valid }\end{array}$} \\
\hline Pinjaman lunak: & Penyaluran dana & & & \\
\hline Pembinaan: & $\begin{array}{l}\text { Monitoring } \\
\text { penggunaan dana }\end{array}$ & 0.791 & 0.000 & Valid \\
\hline & $\begin{array}{l}\text { Evaluasi } \\
\text { perkembangan } \\
\text { usaha }\end{array}$ & 0.678 & 0.000 & Valid \\
\hline & $\begin{array}{l}\text { Penyusunan profil } \\
\text { mitra binaan }\end{array}$ & 0.896 & 0.000 & Valid \\
\hline \multirow[t]{3}{*}{ Pelatihan: } & $\begin{array}{l}\text { Pendidikan dan } \\
\text { pelatihan }\end{array}$ & 0.845 & 0.000 & Valid \\
\hline & $\begin{array}{l}\text { Proses } \\
\text { komputerisasi } \\
\text { pembukuan }\end{array}$ & 0.421 & 0.000 & Valid \\
\hline & $\begin{array}{l}\text { Display } \\
\text { produk/prestasi } \\
\text { mitra binaan }\end{array}$ & 0.805 & 0.000 & Valid \\
\hline \multirow[t]{3}{*}{ Pemasaran } & Pameran & 0.847 & 0.000 & Valid \\
\hline & Promosi & 0.784 & 0.000 & Valid \\
\hline & Cluster & 0.795 & 0.000 & Valid \\
\hline
\end{tabular}

Sumber: Perhitungan SPSS 
Reliabilitas adalah alat untuk mengukur suatu kuesioner yang merupakan indikator dari variabel atau konstruk. Suatu kuesioner dikatakan reliabel atau handal jika jawaban seseorang terhadap pertanyaan adalah konsisten atau stabil dari waktu ke waktu (Ghozali, 2016: 47). Pengujian reliabilitas dilakukan hanya pada indikator- indikator konstruk yang telah melalui pengujian validitas, dan dinyatakan valid. Program SPSS memberikan fasilitas untuk menguji reliabilitas dengan menggunakan uji statistik Cronbach Alpha. Suatu variabel dikatakan reliabel jika memberikan nilai Cronbach Alpha > 0,70 (Ghozali, 2016: 47).

Tabel 3.4 Uji Reliabilitas

\begin{tabular}{llllll}
\hline Variabel : & & Cronbach Alpha & Kriteria & Keterangan \\
\hline $\begin{array}{l}\text { Realisasi Program } \\
\text { (Persero) }\end{array}$ & PT & INKA & 0,926 & $>0,7$ & Reliabel \\
Harapan Program Mitra Binaan & 0,943 & $>0,7$ & Reliabel \\
\hline
\end{tabular}

Sumber: Perhitungan SPSS

Uji normalitas bertujuan untuk menguji apakah data penelitian berdistribusi normal apa tidak. Penelitian yang baik adalah berdistribusi normal atau mendekati normal. Untuk menguji normalitas data, pada penelitian ini menggunakan uji statistik nonparametrikKolmogrov-Smirnov

(Ghozali, 2016: 154).

Hasil pengujian normalitas pada realisasi program dengan uji statistik non-parametrikKolmogrovSmirnov menunjukkan bahwa besarnya nilai Kolmogrov-Smirnov adalah 0,727 dengan asymp. Sig. (2tailed) 0,667. Dan hasil pengujian normalitas pada harapan program dengan uji statistik nonparametrikKolmogrov-Smirnov menunjukkan bahwa besarnya nilai Kolmogrov-Smirnov adalah 0,609 dengan asymp. Sig. (2-tailed) 0,852. Karena hasil signifikan keduanya lebih besar dari 0.05, maka dapat disimpulkan data berdistribusi normal dan layak dipakai untuk penelitian. 


\section{PEMBAHASAN}

Berdasarkan teori Kotler dan Lee dalam Solihin (2008), bentuk pelaksanaan program CSR seperti ini termasuk dalam kategori bentuk pelaksanaan Socially Responsible Bussiness karena melalui program kemitraan dan bina lingkungan artinya perusahaan mendukung program sosial dengan tujuan meningkatkan kesejahteraan komunitas dan memelihara lingkungan hidup yang melibatkan perusahaan dengan masyarakat secara umum.

Dengan demikian maka manfaat yang akan diterima perusahaan dalam program kemitraan dan bina lingkungan adalah meningkatnya kesan baik komunitas terhadap karyawan karena adanya personil khusus yang mengelola dan berhubungan langsung dengan mitra binaan sebagai penerima program PKBL, menciptakan preferensi masyarakat terhadap perusahaan, serta timbulnya citra positif dari pemerintah karena perusahaan telah mematuhi anjuran pemerintah dalam peraturan dan UU mengenai tanggung jawab sosial perusahaan.

Weiss (1972) menyatakan bahwa untuk mengukur efektivitas suatu program dilakukan berdasarkan dampak dari suatu program yang mengarah pada pencapaian dari serangkaian tujuan yang telah ditetapkan dan sebagai sarana untuk memberi kontribusi (rekomendasi) dalam membuat keputusan dan perbaikan program pada masa mendatang.

Untuk itu dalam penelitian ini dilakukan pengukuran efektivitas berdasarkan realisasi tujuan dari program kemitraan dan bina lingkungan yang dilaksanakan pada mitra binaan PT INKA (Persero). Penilaian efektivitas Program Kemitraan dan Bina Lingkungan PT. INKA (Persero) yang dirasakan oleh responden dapat dilihat berdasarkan tabel dibawah 
Tabel 4.1 Efektivitas tujuan Program Kemitraan dan Bina Lingkungan PT INKA (Persero)

\begin{tabular}{clcc}
\hline & PKBL PT INKA (Persero) & $\begin{array}{c}\text { Skor } \\
\text { Rataan }\end{array}$ & Keterangan \\
\hline Pinjaman & Penyaluran dana & 4,56 & Sangat Efektif \\
Lunak: & & & \\
Pembinaan: & Monitoring penggunaan dana & 3,45 & Efektif \\
& Evaluasi perkembangan usaha & 3,50 & Efektif \\
& Penyusunan profil mitra binaan & 3,29 & Kurang Efektif \\
Pelatihan: & Pendidikan dan pelatihan & 3,53 & Efektif \\
& Proses komputerisasi pembukuan & 2,95 & Kurang Efektif \\
& Display produk/prestasi mitra binaan & 3,41 & Efektif \\
Pemasaran: & Pameran & 3,53 & Efektif \\
& Promosi & 3,56 & Efektif \\
& Cluster & 3,30 & Kurang Efektif \\
& Secara keseluruhan & 3,50 & Efektif \\
\hline
\end{tabular}

Sumber: Diolah

Hasil menunjukkan bahwa yang dimiliki perusahaan (Rangkuti Program Kemitraan dan Bina dalam Fitriyani, 2011). Atribut-atribut Lingkungan berdasarkan hasil tujuan Program Kemitraan dan Bina realisasi tujuan program diatas Lingkungan PT INKA (Persero) memiliki skor rataan secara meliputi, Program Pinjaman Lunak keseluruhan sebesar 3,50 yang artinya (atribut: Penyaluran dana), Program tujuan Program Kemitraan dan Bina Pembinaan (atribut: Monitoring Lingkungan tercapai secara efektif. penggunaan dana, Evaluasi Ini artinya H1 Diterima bahwa perkembangan usaha dan Penyusunan Program PKBL berpengaruh terhadap profil mitra binaan), Program Efektivitas Program.

\section{Importance Performance}

Analysis (IPA) adalah salah satu cara yang dapat menggambarkan tingkat kesesuaian antara Kepentingan (harapan) dengan kinerja (realisasi) dari atribut-atribut tujuan program
Pelatihan (atribut: Pendidikan dan pelatihan, Proses komputerisasi pembukuan dan Display produk/prestasi mitra binaan) dan Program Pemasaran (atribut: Pameran, Promosi dan Cluster). 
Tabel 4.2 Tingkat Kesesuaian Harapan dan Realisasi Program

Program Skor Rataan $\quad$ X

(Realisasi) (Harapan)

\begin{tabular}{|c|c|c|c|}
\hline \multirow{4}{*}{$\begin{array}{l}\text { Pinjaman lunak: } \\
\text { Pembinaan: }\end{array}$} & & \multirow{2}{*}{4,56} & \multirow{2}{*}{4,67} \\
\hline & Penyaluran dana & & \\
\hline & Monitoring penggunaan dana & 3,45 & 3,53 \\
\hline & Evaluasi perkembangan usaha & 3,50 & 3,59 \\
\hline & Penyusunan profil mitra binaan & 3,29 & 3,34 \\
\hline \multirow{3}{*}{ Pelatihan: } & Pendidikan dan pelatihan & 3,53 & 3,57 \\
\hline & Proses komputerisasi pembukuan & 2,95 & 2,84 \\
\hline & $\begin{array}{l}\text { Display produk/prestasi mitra } \\
\text { binaan }\end{array}$ & 3,41 & 3,52 \\
\hline \multirow[t]{3}{*}{ Pemasaran: } & Pameran & 3,53 & 3,46 \\
\hline & Promosi & 3,56 & 3,53 \\
\hline & Cluster & 3,30 & 3,21 \\
\hline
\end{tabular}

Sumber: Diolah

Matriks IPA terdiri dari empat kuadran yang masing-masing menjelaskan keadaan yang berbeda. Kuadran-kuadran tersebut dapat dipilih perusahaan untuk mempertimbangkan kedepannya sejauh mana efektivitas program yang menjadi harapan dan realisasi program yang masih harus dipertahankan atau dihilangkan. Berikut gambar matriks IPA pada penelitian ini:

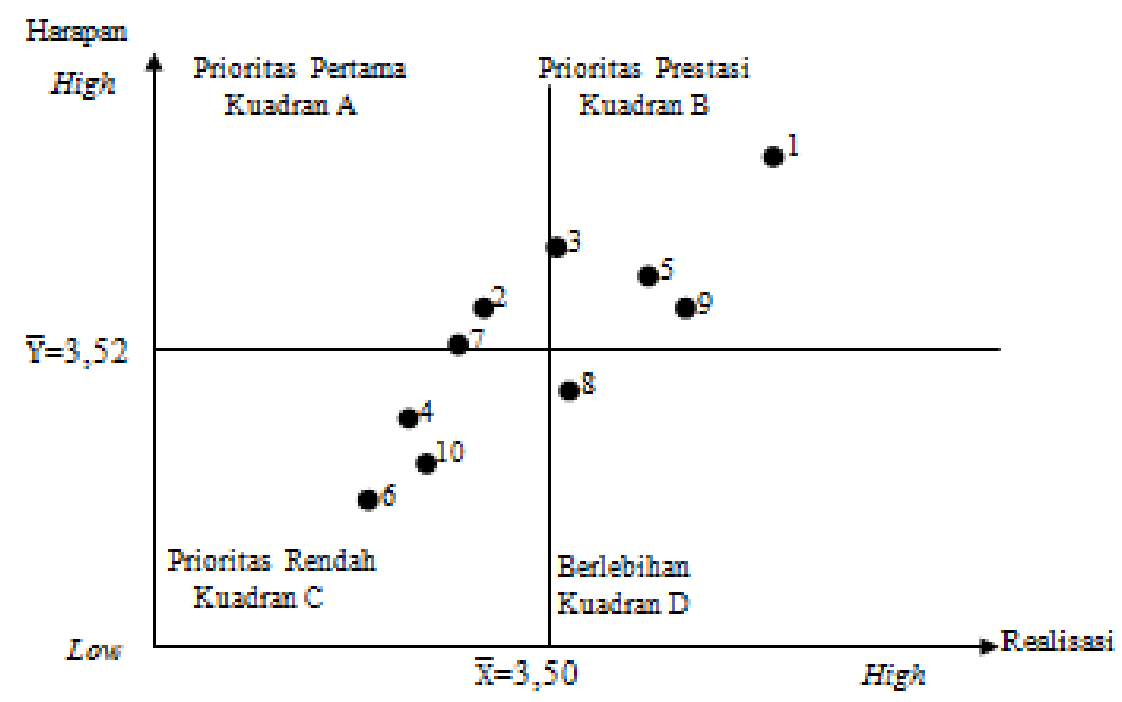

Sumber: Diolah

Gambar 4.1 Matriks IPA 


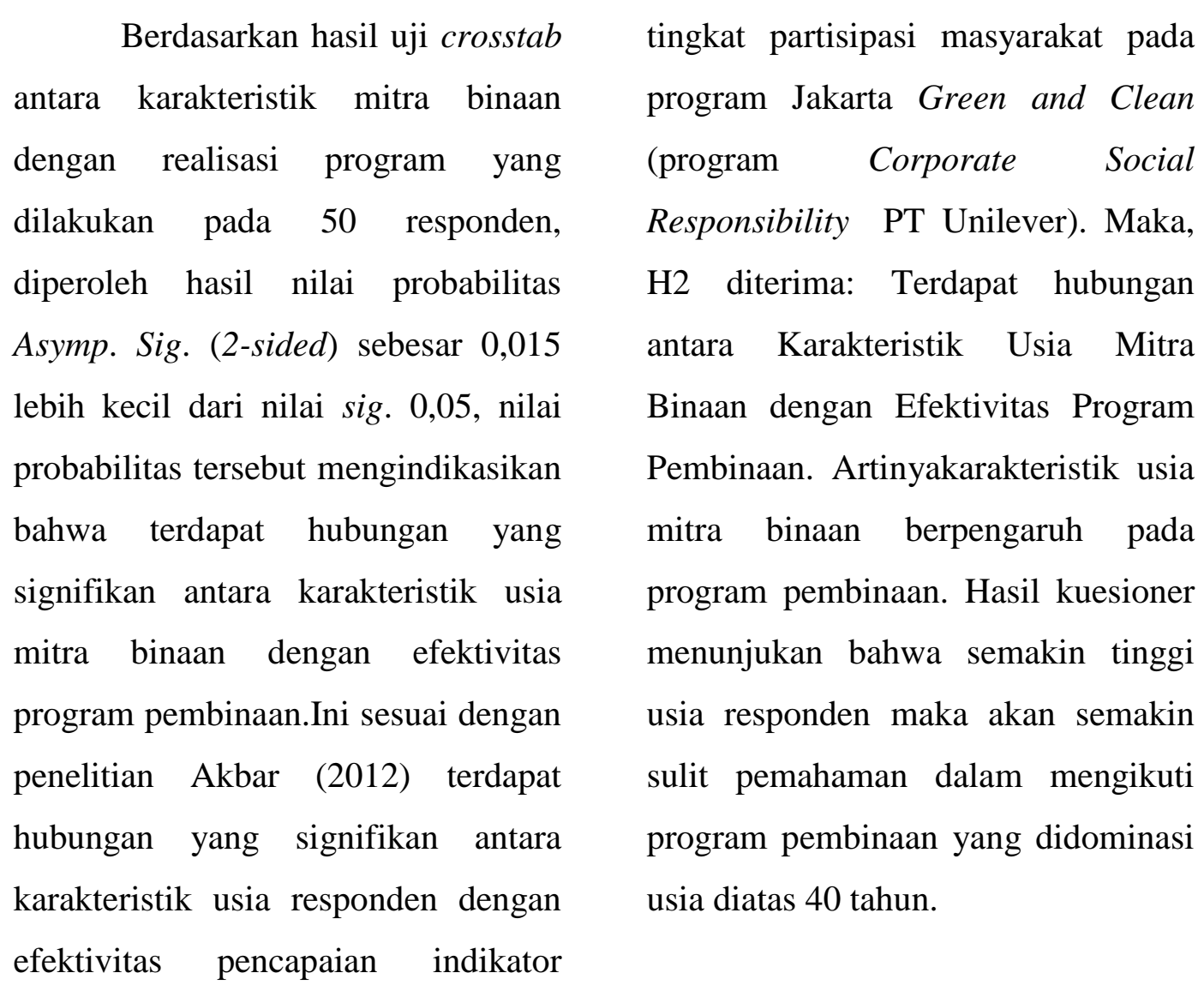

Tabel 4.3 Hubungan antara Usia dengan Pembinaan.

\begin{tabular}{lcccc}
\hline \multirow{2}{*}{ Usia } & \multicolumn{2}{c}{ Pembinaan } & & \\
& Tidak Efektif & Kurang Efektif & Efektif & Sangat Efektif \\
\hline 24-30 Tahun & 0 & 2 & 0 & 2 \\
31-40 Tahun & 5 & 4 & 7 & 3 \\
>40 Tahun & 7 & 2 & 17 & 1 \\
Total & 12 & 8 & 24 & 6 \\
\hline
\end{tabular}

Sumber: Perhitungan SPSS 
Jurnal Akuntansi, Prodi. Akuntansi-FEB, UNIPMA, Vol. 1, No.2, April 2018

KESTIMPULAN

Berdasarkan pada hasil penelitian mengenai efektivitas program kemitraan dan bina lingkungan PT INKA (Persero) pada UMKM, maka diperoleh kesimpulan bahwa Efektivitas Program Kemitraan dan Bina Lingkungan PT INKA (Persero), dari segi realisasi ketercapaian tujuan program, secara keseluruhan tujuan program dapat dikatakan efektif. Dan program yang paling tinggi efektivitasnya adalah program pinjaman lunak. Berdasarkan hasil Tabulasi Silang (Crosstab) yang terdapat hubungan karakteristik mitra binaan dengan efektivitas program hanya antara karakteristik umur mitra binaan dengan program pembinaan.

\section{SARAN}

1. Bagi Perusahaan:

a. Perusahaan perlu mempertahankan program pinjaman lunak dengan bunga $0,5 \%$ perbulan serta kemudahan persyaratannya.

b. Perusahaan memberikan pemahaman mengenai peran penting kegiatan pameran terhadap usaha mitra agar pelaksanaan program pameran dapat ditingkatkan

c. Perlu ditingkatkan sosialisasi kepada masyarakat sekitar perusahaan maupun UMKM agar mereka mengetahui secara jelas tentang adanya Program Kemitraan dan Bina Lingkungan pada PT INKA (Persero).

2. Bagi Akademisi:

a. Untuk penelitian selanjutnya, perlu diteliti ulang terhadap efektivitas program, program penyusunan profil mitra binaan, program proses komputerisasi pembukuan, dan program cluster masih rendah apa tidak nilai kefektifan dan harapan dari mitra binaan sehingga kedepannya program-program tersebut perlu dipertimbangkan untuk ditingkatkan atau digantikan dengan program kemitraan dan bina lingkungan yang lain. 
Akbar, Ilham Nur. (2012). Analisis

Efektivitas Pencapaian

Indikator Pelaksanaan Program

CSR Lingkungan Jakarta Green

And Clean PT Unilever Tbk

Dan Dampaknya Terhadap

Citra Perusahaan. Bogor:

Fakultas Ekonomi dan

Manajemen. Institut Pertanian

Bogor.

Bahannoer, Noni (2009). Pengaruh

Pemberian Kredit Terhadap

Perkembangan Usaha Kecil

Dan Menengah Pada Program

Kemitraan Dan Bina

Lingkungan

(PKBL)

PT.PERTAMINA (Persero).

Medan: FEB. Universitas

Sumatera Utara.

Fitriyani, Intan (2011). Analisis

Efektivitas Program Kemitraan

PT Bank X Dengan Usaha

Kecil Di Bogor. Bogor:

Fakultas Ekonomi dan

Manajemen. Institut Pertanian

Bogor.

Ghozali, imam. (2016). Aplikasi

Analisis Multivariete Dengan

Program IBM SPSS 23;
(Cetakan ke 8). Semarang: Badan penerbit Universitas

Diponegoro.

Handayani, Retno., Darsono., Widiyanti, Emi. (2014). Efektivitas Kemitraan Pabrik Gula (PG) Mojo Terhadap Kesejahteraan Rumah Tangga Petani Tebu Di Kabupaten Sragen.

http://bumn.go.id/inka

Indrawan, Rully., Yaniawati, R., Poppy. (2014). Metodologi Penelitian Kuantitatif, Kualitatif, dan Campuran untuk Manajemen, Pembangunan, dan Pendidikan. Bandung: Refika Aditama.

Kadir. (2015). Statistika Terapan Konsep, Contoh dan Analisis Data dengan Program SPSS/Lisrel dalam Penelitian; (Edisi ke 2). Jakarta: PT Raja Grafindo Persada.

Keputusan Menteri Keuangan Republik Indonesia Nomor: 60/KMK.016/1996 pada Pasal 3 Keputusan Menteri Keuangan Republik Indonesia Nomor: 
Jurnal Akuntansi, Prodi. Akuntansi-FEB, UNIPMA, Vol. 1, No.2, April 2018

3ाठ/KMाK.णाठ/1994 tentang

Pedoman Pembinaan Usaha

Kecil dan Koperasi Melalui

Pemanfaatan Dana Dari Bagian

Lembaga BUMN.

Laporan Tahunan PKBL PT INKA

(Perseo) Tahun 2013-2015.

Sugiyono. (2013).Metode Penelitian

Kuantitatif, Kualitatif dan

$R \& D ; \quad$ (Cetakan ke 19).

Bandung: Alfabeta.

Supriadinata, Wahyu., Goestaman,

Imanuel. (2013). Analisis

Efektivitas Corporate Social

Responsibility (CSR) Dalam

Menyeleseikan Masalah Sosial

Lingkungan Perusahaan (Studi

Kasus PT PERTAMINA

(Persero) Unit Pemasaran

TBBM Depot Ende). Jurnal

Ilmiah Mahasiswa Universitas

Surabaya Vol. 2 No. 1.

Suyanto, M. (2007). Strategi

Management Global Most

Admired

CompaniesPerusahaan yang

Paling Dikagumi Dunia.

Yogyakarta: Andi Offset.

Tanto, Dwi., Dewi, Sri Murni., Budio,

Sugeng, P. (2012). Faktor-

Faktor Yang Mempengaruhi
Produktıvitas Pekerja Pada

Pengerjaan Atap Baja Ringan

Di Perumahan Green Hills

Malang. Jurnal Rekayasa Sipil/

Volume 6, No.1-2012 ISSN

1978-5658.

Widodo, Joko. (2017). Analisis Kebijakan Publik Konsep dan Aplikasi Analisis Proses Kebijakan Publik. Malang: Media Nusa Kreatif.

www.hukumonline.com (Undangundang Pasal 74 No.40 Tahun 2007 Tentang Perseroan Terbatas).

Yulianti, Devi (2012). Efektivitas Program PTPN 7 Peduli Di PTPN VII (Persero) Lampung (Suatu Evaluasi Atas Program CSR). Tesis. Depok: FISIP Program Pacasarjana. Universitas Indonesia 